\title{
In memory of Paolo Costantino (1955-2020)
}

\author{
Francesco Berti ${ }^{1} \cdot$ Roberto Adamo $^{1}$
}

Published online: 9 January 2021

(C) Springer Science+Business Media, LLC, part of Springer Nature 2021
Paolo Costantino earned his bachelor degree in Chemistry at the University of Pisa in 1979, with a thesis in Organic Chemistry having Prof. Francesco Ciardelli and Prof. O. Pieroni as supervisors.

Initially he had some academic experiences as Teaching Assistant "ad horas" in Organic Chemistry and Fellow at Biophysics Institute at CNR of Pisa (1979-1980) and as Fellow of Organic Chemistry Laboratory at the School of Pharmacy at the University of Pisa (1980-1981) working on the 'Synthesis and characterization of photochromic polypeptides' and 'Investigations on pharmacologically active phenantridone derivatives and synthesis of epoxycyclohexanes and derivatives' respectively. In 1982 he started his industrial career, joining the Sclavo S.p.A. company located in Siena.

Over his 35 years in the industrial setting, he experienced the various acquisitions of Siena Research and Development Centre, from Sclavo S.p.A., Immunobiological Research Institute Siena (I.R.I.S.), Chiron Vaccines, Novartis Vaccines, until the recent transition to GSK. During these years, Paolo covered several roles with increased responsibility, Scientist at the Research \& Development Department (1982-1992), Head of Glycoconjugate Vaccines Laboratory (1992-1996), Head of Glycoconjugate Vaccines Laboratory (1996-1998), Global Head Process Development (19992003), Head Technology Development, Italy (2003-2006), Global Head of Vaccine Chemistry (2006-2012), Head

This article belongs to the Topical Collection: Glycoconjugate vaccines: classic and novel approaches

Francesco Berti

francesco.berti@novartis.com

Roberto Adamo

roberto.x.adamo@gsk.com

1 GSK, Research and Development Centre, Via Fiorentina 1, 53100 Siena, Italy
Protein Biochemistry (2012-2015). In 2016 Paolo was appointed as Global Head of the Conjugate Platform, which he led until his retirement in 2018.

Through his entire career, Paolo gave a fundamental contribution to research and development of glycoconjugate vaccines, that in the 80 s was seeing enormous progress.

Paolo can be considered the father of the Neisseria meningitidis ACWY conjugated vaccine and he contributed to bring from the bench to the market glycoconjugate vaccines against Haemophilus influenzae type $\mathrm{b}$ and Neisseria meningitidis which have saved millions of lives in many countries. He provided a massive impact globally in the research of a series of carbohydrate-based vaccines to target a number of infectious diseases caused by pathogenic bacteria, including N. meningitidis serogroup X, group B and A Streptococci, Staphylococcus aureus and Clostridium difficile, and fungi, such as Candida albicans.

He also gave an important pulse to the creation of the Novartis Vaccines Institute for Global Health, now GSK Vaccines Institute for Global Health, where vaccines for the emerging countries, including the one recently approved against Salmonella Typhi, have been developed.

Paolo authored and co-authored more than 70 published scientific papers and reviews and a very large numbers of patents, contributing to the advancement of glycoconjugate vaccines. His contribution has been recognized through the Derek Horton Award in Industrial Carbohydrate Chemistry from the American Chemical Society given to the GSK team in 2016 and the Giancarlo Berti's medal from the Italian Chemical Society that he received in 2018.

$\mathrm{He}$ also spent impressive effort to support $\mathrm{PhD}$ fellow and young scientists and coaching his younger colleagues, leaving a precious legacy of scientific knowledge and care of people.

He will be greatly missed by his colleagues, friends and most of all by his family.

Publisher's note Springer Nature remains neutral with regard to jurisdictional claims in published maps and institutional affiliations. 